\title{
Stereoselective $\alpha$-Sialylation with Sialyl Pentenoates as Donors and PhSeOTf as the Activator ${ }^{\dagger}$
}

\author{
Bo-Young Lee, Young-Kil Chang, Dae-Hwan Suk, and Kwan Soo Kim* \\ Center for Bioactive Molecular Hybrids and Department of Chemistry, Yonsei University, Seoul 120-749, Korea \\ *E-mail:kwan@yonsei.ac.kr \\ Received November 29, 2009, Accepted December 30, 2009
}

Key Words: Glycosyl pentenoate, $\alpha$-Sialylation, Glycosylation, Phenylselenyl triflate

Sialic acids are a family of monosaccharides comprising about 40 members which have in common neuraminic acid (Neu) (5-amino-3,5-dideoxy-D-glycero-D-galacto-nonulosonic acid). Since the first discovery of $N$-acetylneuraminic acid (Neu5Ac, 1) from brain glycolipids or salivary mucins, many of sialic acids have been known to occur in animal and some microorganisms. ${ }^{1}$ Because they occupy the terminal position on macromolecules and cell membranes and thus are involved with essential functional roles in many biological and pathological phenomena, ${ }^{2,3}$ sialic acids have become a family of the most important molecules of life. The lead member of the family, Neu5Ac (1), which is found in important naturally occurring glycoconjugates and oligosaccharides, is typically linked to galactose through an $\alpha 2 \rightarrow 3$ or an $\alpha 2 \rightarrow 6$ linkage or is polymerized in the form of an $\alpha 2 \rightarrow 8$ or an $\alpha 2 \rightarrow 9$ linkage. ${ }^{3}$ Over the years, a number of strategies for the stereoselective construction of the equatorial $\alpha$-sialyl linkages have been develop$\mathrm{ed}^{4}$ and the main focus was on the utilization of various leaving groups on sialyl donors such as phosphite, ${ }^{5}$ hydroxy group, ${ }^{6}$ $N$-phenyltrifluoroacetimidate, ${ }^{7}$ xanthate, ${ }^{8}$ halide, ${ }^{9}$ sulfide, ${ }^{10}$ and 1 -adamantanyl thiosialoside. ${ }^{11} \mathrm{We}$ introduced previously four new glycosyl donors having new leaving groups for stereoselective glycosylations: 2'-carboxybenzyl (CB) glycosides, ${ }^{12} 2^{\prime}-$ (benzyloxycarbonyl)benzyl glycosides, ${ }^{13}$ glycosyl $p$-bromophenyl phthalates, ${ }^{14}$ and glycosyl phthalates. ${ }^{15}$ The efficiency and stereoselectivity of sialylations with sialyl donors having these new leaving groups such as CB sialosides, 2'-(benzyloxycarbonyl)benzyl sialosides, sialyl $p$-bromophenyl phthalates, and sialyl phthalates were not satisfactory. Fortunately, however, we were able to achieve the stereoselective $\alpha$-sialylation employing the glycosyl pentenoates/PhSeOTf method, which also we introduced previously for the stereoselective $\beta$-mannosylation and other glycosylations. ${ }^{16}$ Herein we report the efficient, stereoselective $\alpha$-sialylation method by using $N$-acetylneuraminyl (Neu5Ac) pentenoate $\mathbf{2}$ and $N$-trifluoroacetylneuraminyl (Neu5TFA) pentenoate $\mathbf{3}$ as donors with PhSeOTf as a promoter. Although there has been a report on the preparation of sialylation with $\mathbf{2}$ by other workers, they reported the poor stereoselectivity of the sialylation of only one benzylic alcohol with 2 employing other promoters but failed to report the sialylation of sugars. ${ }^{17}$

Sialyl pentenoates $\mathbf{2}$ and $\mathbf{3}$ were readily prepared by esteri-

${ }^{\dagger}$ This paper is dedicated to Professor Sunggak Kim on the occasion of his honorable retirement. fication of corresponding sialyl anomeric hydroxy sugars $4^{18}$ and $\mathbf{5},{ }^{7}$ respectively, with 4-pentenoic acid using $N, N^{\prime}$-diisopropylcarbodiimide (DIC) in the presence of a catalytic amount of 4-dimethylaminopyridine (DMAP) as shown in Scheme 1. At first, we examined sialylations of primary hydroxy acceptor $\mathbf{6}$ with the donor $\mathbf{2}$ employing PhSeOTf as the activating agent in the presence of 2,4,6-tri-tert-butylpyrimidine (TTBP) ${ }^{19}$ and $4 \mathrm{~A}$ molecular sieves at -78 or $-40{ }^{\circ} \mathrm{C}$ to $0{ }^{\circ} \mathrm{C}$ in four different solvents. The sialylation of $\mathbf{6}$ with $\mathbf{2}$ in dichloromethane was not $\alpha$-selective but rather $\beta$-selective, yielding sialyl disaccharides $7(\alpha / \beta=1: 13.4)$ with a large excess of the $\beta$-anomer in $72 \%$ yield (entry 1 in Table 1). 1,4-Dioxane and toluene, however, were found to be not proper solvents for the present sialylation (entries 2 and 3 in Table 1), whereas the sialylation in acetonitrile produced sialyl disaccharide $7(\alpha / \beta=3.3: 1)$, favoring the $\alpha$-anomer in $54 \%$ yield (entry 4 ). In this stage, we realized that the base TTBP might not be necessary for the present sialylation, even though it was essential for trapping triflic acid generated during glycosylations in our original work, ${ }^{16}$ because there were no acid-labile protecting groups in both donors and acceptors in the present work. The sialylation of $\mathbf{6}$ with $\mathbf{2}$ in acetonitrile without TTBP at $-40{ }^{\circ} \mathrm{C}$ to $0{ }^{\circ} \mathrm{C}$ was more satisfactory than those under other conditions, affording sialoside $7(\alpha / \beta=5.5: 1)$ with an excess of the $\alpha$-anomer in $91 \%$ yield (entry 5). Acetonitrile is known to facilitate the formation of equatorial glycosyl bonds in several glycosylation reactions. ${ }^{20}$ Acetonitrile, in the present study, might interact with sialyl oxocarbenium ions generated during the sialylations and the resulting axial $\beta$-sialyl nitrilium ion might be one of reactive inter-

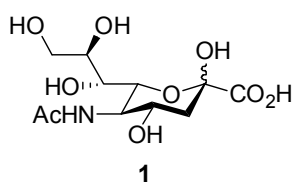

Figure 1. $N$-Acetylneuraminic acid (Neu5Ac).

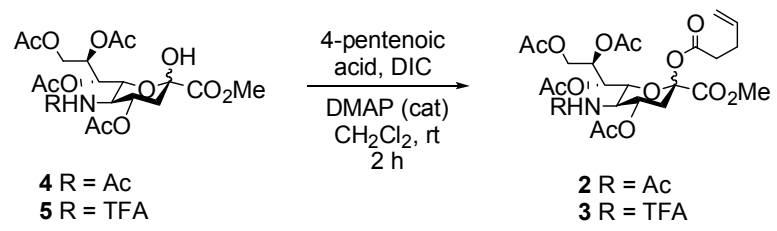

Scheme 1. Synthesis of sialyl pentenoates $\mathbf{2}$ and $\mathbf{3}$ 
Table 1. Sialylations of acceptor $\mathbf{6}$ with sialyl donor $\mathbf{2}$ in different solvents

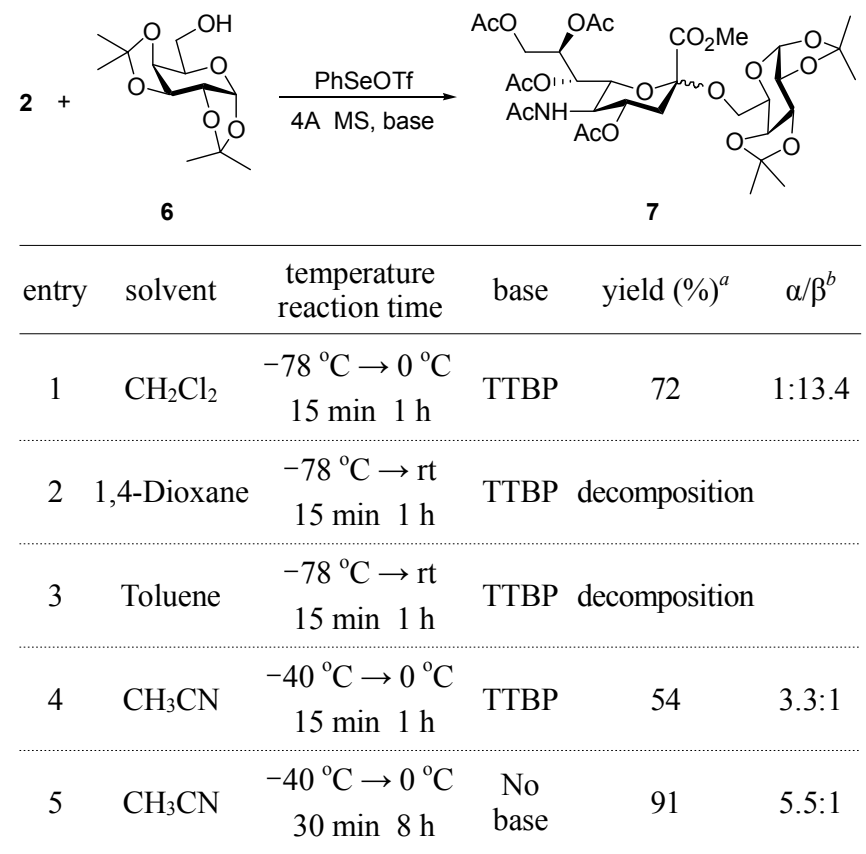

${ }^{a}$ Determined after isolation. ${ }^{b}$ The ratio was determined by LC-mass.

Table 2. Sialylations of various acceptors 8-12 with sialyl donor 2 in acetonitrile

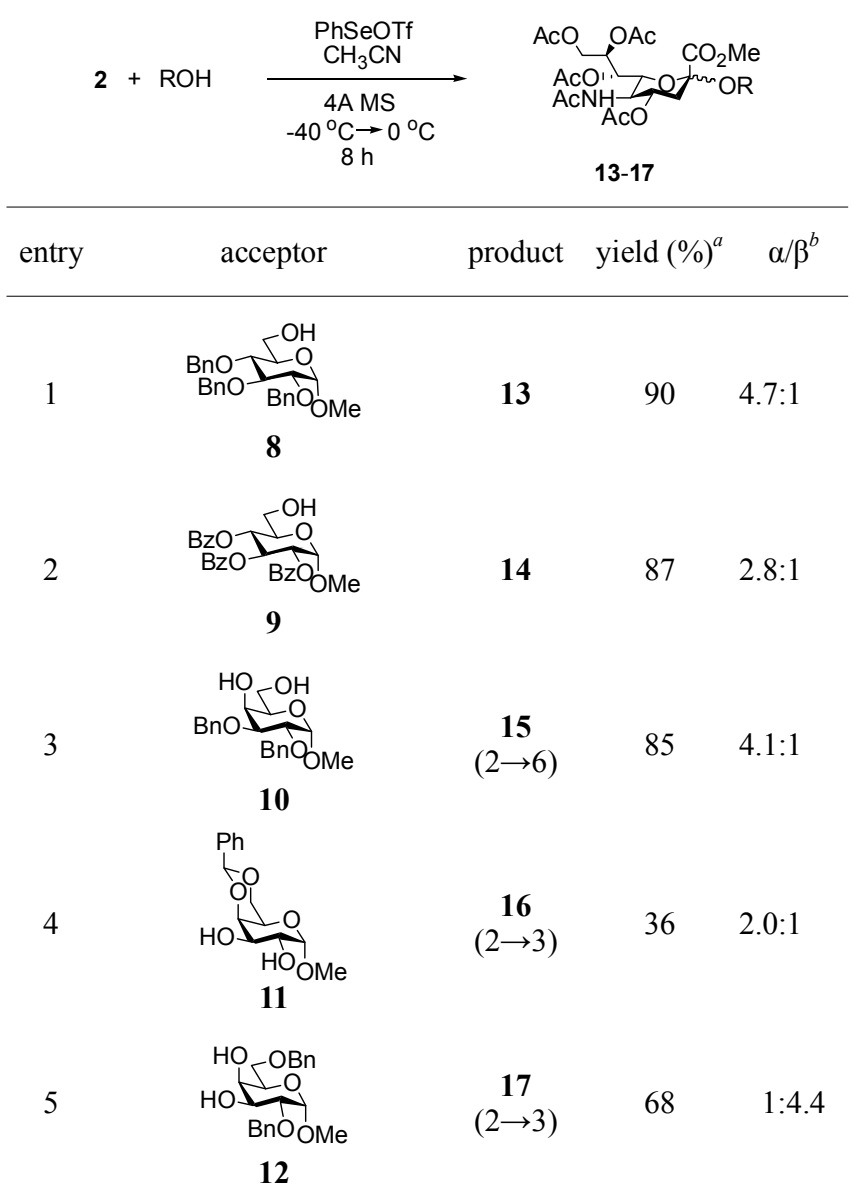

${ }^{a}$ Determined after isolation. ${ }^{b}$ The ratio was determined by LC-mass. mediates. The better result without the base, namely, TTBP might be ascribed to the interference of the base with activation of pentenoates by PhSeOTf in the present sialylation. ${ }^{21}$

Therefore, sialylations of various acceptors with sialyl donors $\mathbf{2}$ and $\mathbf{3}$ were carried out employing PhSeOTf in acetonitrile in the presence of $4 \mathrm{~A}$ molecular sieves (MS) at $-40{ }^{\circ} \mathrm{C}$ to $0{ }^{\circ} \mathrm{C}$ as a standard reaction condition. Sialylations of primary hydroxy acceptors 8 and 9 with 2 afforded disaccharides $13(\alpha / \beta=4.7: 1)$ and $14(\alpha / \beta=2.8: 1)$, favoring $\alpha$-anomers in high yields (entries 1 and 2 in Table 2). In the sialylation of dihydroxy acceptor $\mathbf{1 0}$ with $\mathbf{2}$, the primary hydroxy group of $\mathbf{1 0}$ selectively reacted, yielding sialyl $(2 \rightarrow 6)$ galactoside $15(\alpha / \beta=4.1: 1)$ with an excess of the $\alpha$-anomer in $85 \%$ yield (entry 3 ). The sialylation of secondary dihydroxy acceptor 11 with 2 provided $2 \rightarrow 3$ sialyl disaccharide $16(\alpha / \beta=2.0: 1)$ with a slight excess of the $\alpha$-anomer in poor yield (entry 4 ) whereas the sialylation of secondary dihydroxy acceptor $\mathbf{1 2}$ with $\mathbf{2}$ afforded $2 \rightarrow 3$ sialyl disaccharide $17(\alpha / \beta=1: 4.4)$ with an excess of the $\beta$-anomer in $68 \%$ yield (entry 5). The regioselectivities shown by dihydroxy acceptors 10, 11, and 12 in the present sialylation are also known in other glycosylations, especially in sialylations with other donors. ${ }^{4}$ The stereochemistries at the newly generated anomeric centers of the product sialyl disaccharides have been unequivocally determined on the basis of four characteristic parameters of their NMR spectra: $\delta \mathrm{H}^{\prime}{ }^{\mathrm{eeq}}{ }^{22} \delta \mathrm{H} 4^{\prime},{ }^{9,23} J_{\mathrm{H} 7^{\prime}, \mathrm{H} 8^{\prime}},{ }^{9,24}$ and $\Delta \delta\left\{\mathrm{H} 9^{\prime} \mathrm{a}-\right.$ H9'b ${ }^{24}$

To improve the efficiency and stereoselectivity of the sialylation with sialyl pentenoates, we considered Neu5TFA pentenoate $\mathbf{3}$ as a sialyl donor having the $5-N$-trifluoroacetyl (TFA) group instead of Neu5Ac pentenoate 2 having 5- $\mathrm{N}$-acetyl (Ac) group. In fact, the trifluoroacetyl group has been previously recognized as the better protecting group for the 5-amino group of the sialyl donor than the acetyl group in the sialylation with thiosialosides. ${ }^{25}$ With Neu5TFA pentenoate $\mathbf{3}$ as the sialyl donor, sialylations of primary hydroxy acceptors $\mathbf{8}$ and $\mathbf{1 8}$ bearing benzyl-protecting groups were highly $\alpha$-selective, yielding exclusively $\alpha$-disaccharides $\mathbf{2 0}$ and $\mathbf{2 1}$, respectively, in high yields (entries 1 and 2 in Table 3 ). Sialylations of primary hydroxy acceptors 9 and 19 possessing benzoyl-protecting groups with 3 as the sialyl donor, on the other hand, were less $\alpha$-selective, providing sialyl disaccharides $22(\alpha / \beta=4.2: 1)$ and $23(\alpha / \beta=$ $3.6: 1$ ), respectively, with an excess of $\alpha$-anomers (entries 3 and 4). The sialylation of dihydroxy acceptor $\mathbf{1 0}$ with $\mathbf{3}$ was regioselective as anticipated and $\alpha$-selective as well, yielding sialyl$(2 \rightarrow 6)$ galactoside $24(\alpha / \beta=5.8: 1)$ with an excess of the $\alpha$-anomer in $88 \%$ yield (entry 5 ). Sialylations of dihydroxy acceptors 11 and 12 with 3 were also regio- and stereoselective, giving sialyl $(2 \rightarrow 3)$ galactosides $25(\alpha / \beta=2.6: 1)$ and $26(\alpha / \beta=4.0: 1)$, respectively, with an excess of $\alpha$-anomers (entries 6 and 7). The results indicate that the trifluoroacetyl group at the $N-5$ position in the sialyl pentenoate, indeed, makes the sialylation more $\alpha$-selective than the acetyl group. Although it has been suggested that the stronger electron-withdrawing trifluoroacetyl group would reduce the nucleophilicity of the amino group, thereby suppressing possible side reactions in glycosylations, ${ }^{25}$ the origin of the enhanced $\alpha$-selectivity by trifluoroacetyl group is unclear as yet. Nevertheless, it could be mentioned that electron-withdrawing groups even at remote positions of donors 
Table 3. Sialylations of various acceptors 8-12, 18, and 19 with sialyl donor $\mathbf{3}$ in acetonitrile

\begin{tabular}{|c|c|c|c|c|}
\hline $3+$ & $\mathrm{ROH}$ & 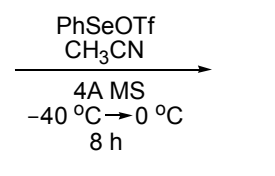 & \multicolumn{2}{|c|}{$\begin{array}{c}\mathrm{OAc} \mathrm{CO}_{2} \mathrm{Me} \\
\mathbf{2 0 - 2 6}\end{array}$} \\
\hline entry & acceptor & product & yield $(\%)^{a}$ & $\alpha / \beta^{b}$ \\
\hline 1 & 8 & 20 & 85 & $\alpha$ only \\
\hline 2 & $\frac{\mathrm{BnO}_{\mathrm{OMe}}}{\mathbf{B n O}}$ & 21 & 85 & $\alpha$ only \\
\hline 3 & 9 & 22 & 87 & $4.2: 1$ \\
\hline 4 & $\frac{\mathrm{BzO}_{19}^{\mathrm{BzO}}}{\mathrm{Bz}}$ & 23 & 93 & $3.6: 1$ \\
\hline 5 & 10 & $\begin{array}{c}24 \\
(2 \rightarrow 6)\end{array}$ & 88 & $5.8: 1$ \\
\hline 6 & 11 & $\begin{array}{c}25 \\
(2 \rightarrow 3)\end{array}$ & 85 & 2.6:1 \\
\hline 7 & 12 & $\begin{array}{c}\mathbf{2 6} \\
(2 \rightarrow 3)\end{array}$ & 88 & $4.0: 1$ \\
\hline
\end{tabular}

${ }^{a}$ Determined after isolation. ${ }^{b}$ The ratio was determined by LC-mass.

were found to strongly affect the outcome of stereochemistry in mannopyranosylations by destabilizing the mannosyl oxocarbenium ion intermediates. ${ }^{26}$ It is also difficult to explain at present the fact that the $\alpha$-selectivity of the benzyl-protected acceptors $\mathbf{8}$ and $\mathbf{1 8}$ is more pronounced than that of the benzoylprotected acceptors 9 and $1 \mathbf{1 9}^{27}$

In summary, a new efficient $\alpha$-selective sialylation method was developed employing $N$-trifluoroacetylneuraminyl pentenoate 3 as a glycosyl donor and PhSeOTf as a promoter. $\alpha$ Selectivity was enhanced with trifluoroacetyl-protecting group at the 5-amino functionality of the donor as compared to that with the acetyl group. Acetonitrile was chosen as the solvent for the present sialylation. The present method would be utilized as an alternative to known methods for the $\alpha$-selective sialylation. The synthesis of the GPI anchor of the scrapie prion protein employing the present sialylation method is currently underway.

\section{Experimental Section}

Methyl 4,7,8,9-tetra-O-acetyl-3,5-dideoxy-5-trifluoroacetamido-2-(4-pentenoyl)- $\beta$-D-glycero- $\alpha$-D-galacto-non-2-ulopyranosonate (3). To a solution of methyl 4,7,8,9-tetra- $O$-acetyl3,5-dideoxy-5-trifluoroacetamido- $\beta$-D-glycero- $\alpha$-D-galactonon-2-ulopyranosonate 15 (1.3 g, $2.38 \mathrm{mmol}), 4$-pentenoic acid $(0.37 \mathrm{~mL}, 3.58 \mathrm{mmol})$, and a catalytic amount of DMAP in $\mathrm{CH}_{2} \mathrm{Cl}_{2}(15 \mathrm{~mL})$ was added $N, N^{\prime}$-diisopropylcarbodiimide $(0.56 \mathrm{~mL}, 3.58 \mathrm{mmol})$ at $0{ }^{\circ} \mathrm{C}$. After being stirred at room tem- perature for $2 \mathrm{~h}$, the reation mixture was quenched with $\mathrm{H}_{2} \mathrm{O}$ and then extracted with $\mathrm{CH}_{2} \mathrm{Cl}_{2}$. The combined organic layer was washed with brine, dried over $\mathrm{MgSO}_{4}$, and concentrated in vacuo. The residue was purified by flash column chromatography $\left(\mathrm{CHCl}_{3} / \mathrm{MeOH}, 9: 1\right)$ to afford compound 3 in $83 \%$ yield: colorless amorphous solid, $R_{f}=0.55\left(\mathrm{CHCl}_{3} / \mathrm{MeOH}, 9: 1, \mathrm{v} / \mathrm{v}\right)$; ${ }^{1} \mathrm{H}$ NMR $\left(400 \mathrm{MHz}, \mathrm{CDCl}_{3}\right) \delta 2.05$ (s, 6H), 2.07 (s, 3H), 2.132.18 (m, 4H, H-3ax, OAc), 2.36-2.55 (m, 4H), 2.58 (dd, $J_{3^{\prime} \mathrm{eq}, 4^{\prime}}=$ $\left.4.8 \mathrm{~Hz}, J_{3^{\prime} \text { 'eq, } 3^{\prime}{ }^{\prime a x}}=13.6 \mathrm{~Hz}, 1 \mathrm{H}, \mathrm{H}-3^{\prime} \mathrm{eq}\right), 3.80$ (s, $\left.3 \mathrm{H}\right), 4.08-4.21$ (m, 2H), 4.30 (dd, $J=2.4,10.4 \mathrm{~Hz}, 1 \mathrm{H}$ ), 4.54 (dd, $J=2.4,12.4$ $\mathrm{Hz}, 1 \mathrm{H}), 5.02-5.14(\mathrm{~m}, 3 \mathrm{H}), 5.35-5.44(\mathrm{~m}, 2 \mathrm{H}), 5.76-5.90(\mathrm{~m}$, $1 \mathrm{H}), 6.98\left(\mathrm{~d}, J_{\mathrm{NH}, 5^{\prime}}=9.6 \mathrm{~Hz}, 1 \mathrm{H}, \mathrm{NH}\right) ;{ }^{13} \mathrm{C}$ NMR $(100 \mathrm{MHz}$, $\left.\mathrm{CDCl}_{3}\right) \delta 20.7,20.8,21.0,28.4,33.1,35.9,50.2,53.4,62.2$, $67.7,67.8,71.9,72.1,97.5,115.6,116.2,136.0,157.6,166.1$, 170.2, 170.5, 170.7, 170.8, 171.3. HRMS calcd for $\mathrm{C}_{25} \mathrm{H}_{32} \mathrm{~F}_{3}$ $\mathrm{NO}_{14} \mathrm{Na}[\mathrm{M}+\mathrm{Na}]^{+}, 650.1673$; found, 650.1674 .

General procedure for sialylations with sialyl pentenoates 2 and 3. A solution of $\mathrm{PhSeBr}(0.61 \mathrm{mmol})$ and $\mathrm{AgOTf}(0.61$ $\mathrm{mmol})$ in $\mathrm{CH}_{3} \mathrm{CN}(5 \mathrm{~mL})$ in the presence of $4 \mathrm{~A}$ molecular sieves was stirred for $30 \mathrm{~min}$ at room temperature and cooled to $-40^{\circ} \mathrm{C}$. A solution of glycosyl donor $(0.12 \mathrm{mmol})$ and glycosyl acceptor $(0.18 \mathrm{mmol})$ in $\mathrm{CH}_{3} \mathrm{CN}(3 \mathrm{~mL})$ was then added and the resulting solution was stirred at $-40{ }^{\circ} \mathrm{C}$ for $30 \mathrm{~min}$. After being stirred at $0{ }^{\circ} \mathrm{C}$ for $8 \mathrm{~h}$, the reaction mixture was quenched with saturated aqueous $\mathrm{NaHCO}_{3}(5 \mathrm{~mL})$, diluted with $\mathrm{CH}_{2} \mathrm{Cl}_{2}$, and filtered through Celite ${ }^{\circledR}$. The filtrate was washed with saturated aqueous $\mathrm{NaHCO}_{3}$ and brine, dried over $\mathrm{MgSO}_{4}$, and concentrated in vacuo. The residue was purified by flash column chromatography. The $\alpha / \beta$ ratios of sialylation products were determined on the basis of the integrations of H3'eq peaks of their NMR spectra of the mixtures of $\alpha$ - and $\beta$-anomers and determined more precisely by LC-mass employing with $\mathrm{C}_{18}$ silica HPLC column and $\mathrm{CH}_{3} \mathrm{CN} / \mathrm{H}_{2} \mathrm{O}(7: 3$ or 8:2) eluent.

Acknowledgments. This work was supported by a grant from Korea Science and Engineering Foundation through Center for Bioactive Molecule Hybrids (CBMH). B.-Y.L and D.-H.S. thank the fellowship of the BK 21 program from the Ministry of Education and Human Resources Development.

Supporting Information. General Methods and characterization data are available.

\section{References}

1. (a) Varki, A.; Cummings, R.; Esko, J.; Freeze, H.; Hart, G.; Marth, J. Essentials of Glycobiology; Cold Spring Harbor Laboratory Press: Cold Spring Harbor, 1999; pp 195-209. (b) Schauer, R. In Carbohydrates in Chemistry and Biology; Ernst, B., Hart, G. W., Sinay, P., Eds.; Wiley-VCH: Weinheim, 2000; Vol. 3, pp 227-243.

2. (a) Mammen, M.; Choi, S.-K.; Whitesides, G. M. Angew. Chem. Int. Ed. 1998, 37, 2754-2794. (b) Schauer, R. Glycoconjugate J. 2000, 17, 485-499.

3. Varki, A. Glycobiology 1993, 3, 97-130.

4. (a) Halcomb, R. L.; Chappell, M. D. J. Carbohydr. Chem. 2002, 21, 723-768. (b) Boons, G.-J.; Demchenko, A. V. Chem. Rev. 2000, 100, 4539-4565. (c) Okamoto, K.; Goto, T. Tetrahedron 1990, 46, 5835-5857.

5. (a) Hanashima, S.; Tomiya, T.; Ishikawa, D.; Akai, S.; Sato, K.-I. Carbohydr. Res. 2009, 344, 959-965. (b) Huang, K.-T.; Lin, C.-C. 
Org. Lett. 2005, 7, 4169-4172.

6. Haberman, J. M.; Gin, D. Y. Org. Lett. 2003, 5, 2539-2541.

7. Cai, S.; Yu, B. Org. Lett. 2003, 5, 3827-3830.

8. Martichonok, V.; Whitesides, G. M. J. Org. Chem. 1996, 61, 17021706.

9. Paulsen, H.; Tietz, H. Angew. Chem. Int. Ed. 1982, 21, 927-928.

10. Matsuoka, K.; Onaga, T.; Mori, T.; Sakamoto, J.-I.; Koyama, T.; Sakairi, N.; Hatano, K.; Terunuma, D. Tetrahedron Lett. 2004, $45,9383-9386$

11. Crich, D.; Li, W. J. Org. Chem. 2007, 72, 7794-7797.

12. Kim, K. S.; Kim, J. H.; Lee, Y. J.; Park, J. J. Am. Chem. Soc. 2001, $123,8477-8481$

13. Kim, K. S.; Lee, M. E.; Cho, J. W. Bull. Korean Chem. Soc. 2004 $25,139-142$.

14. Kwon, S. Y.; Lee, B.-Y.; Jeon, H. B.; Kim, K. S. Bull. Korean Chem. Soc. 2005, 26, 815-818.

15. Kim, K. S.; Fulse, D. B.; Baek, J. Y.; Lee, B.-Y.; Jeon, H. B. J. Am. Chem. Soc. 2008, 130, 8537-8547.

16. For glycosyl pentenoates/PhSeOTf, see: (a) Baek, J. Y.; Choi, T. J.; Jeon, H. B.; Kim, K. S. Angew. Chem. Int. Ed. 2006, 45, 74367440. (b) Choi, T. J.; Baek, J. Y.; Jeon, H. B.; Kim, K. S. Tetrahedron Lett. 2006, 47, 9191-9194.

17. For the Neu5Ac pentenoate 2, see: (a) Ikeda, K.; Fukuyo, J.; Sato, K.; Sato, M. Chem. Pharm. Bull. 2005, 53, 1490-1493. Unfortunately, authors of this article did not cite original papers on glycosyl pentenoates, which were first introduced independently by Kunz and coworkers and by Fraser-Reid and colleagues. For glycosyl pentenoates, see: (b) Kunz, H.; Wernig, P.; Schultz, M. Synlett 1990, 631-632. (c) Lopez, J. C.; Frazer-Reid, B. J. Chem.
Soc., Chem. Commun. 1991, 159-161.

18. Mara, A.; Sinay, P. Carbohydr. Res. 1989, 190, 317-322

19. Crich, D.; Smith, M.; Yao, Q.; Picione, J. Synthesis 2001, 323-326.

20. (a) Pougny, J.; Sinay, P. Tetrahedron Lett. 1976, 17, 4073-4076. (b) Lemieux, R. U.; Ratcliffe, R. M. Can. J. Chem. 1979, 57, 12441251. (c) Schmidt, R. R.; Michel, J. J. Carbohydr. Chem. 1985, 4, 141-169.

21. Another base, namely, 2,6-di-t-butyl-4-methylpyridine (DTBMP) completely inhibited the sialylations of acceptors with $\mathbf{2}$ and $\mathbf{3}$ using PhSeOTf.

22. Dabrowski, U.; Friebolin, H.; Brossmer, R.; Supp, M. Tetrahedron Lett. 1979, 20, 4637-4640.

23. van Halbeek, H.; Dorland, L.; Vliegenthart, J. F. G.; Pfeil, R.; Schauer, R. Eur. J. Biochem. 1982, 122, 305-311.

24. Okamoto, K.; Kondo, T.; Goto, T. Bull. Chem. Soc. Jpn. 1987, 60, 637-643.

25. Meo, C. D.; Demchenko, A. V.; Boons, G.-J. J. Org. Chem. 2001, 66, 5490-5497.

26. Baek, J. Y.; Lee, B.-Y.; Kim, K. S. J. Am. Chem. Soc. 2009, 131, 17705-17713.

27. Although the protecting group effects of acceptors on the glycosylation stereochemistry have been observed before, the origin of the effects is unclear as yet. Rationalizations for the protecting group effect on the glycosylation stereochemistry have been mostly donor-based considerations. For examples, see: (a) Mootoo, D. R.; Konradsson, P.; Udodong, U.; Fraser-Reid, B. J. Am. Chem. Soc. 1988, 110, 5583-5584. (b) Fraser-Reid. B.; Lopez, J. C.; Radhakrishnan, K. V.; Mach, M.; Schlueter, U.; Gomez, A. M.; Uriel, C. J. Am. Chem. Soc. 2002, 124, 3198-3199. 